\title{
The Dimensions of Interpersonal Power Inventory: A Validation Study in a Malaysian Organizational Context
}

\author{
Abdul Aziz Rozilah, Hassan Narehan, Shereen Noranee, Mat Som Rohana, and Sharrifah Ali
}

\begin{abstract}
Power can be envisaged as an individual potential to change, control or influence the behavior, attitudes, opinions, objectives, needs, and values of another party. The purpose of this study is to adapt and analyze the validity and reliability of Interpersonal Power, of a Malaysia version IPI(M)) as well as examine and develop the psychometric properties of the IPI(M) construct which integrates 5 subscales-reward, coercive, expert, referent and legitimate powers. A questionnaire survey was administered to 388 executives working directly under Human Resource Managers in the state-owned organization known as Government Link Companies (GLCs). Prior to that, an exploratory factor analysis (EFA) for pilot study was conducted on 44 items of IPI scale to explore the structure underlying the set of questions designed samples. EFA results confirmed the measurement scale in this study satisfactorily showed a five-factor structure: Reward, Coercive, Legitimate, Expert, and Referent with 25 items remained. Then a confirmatory factor analysis (CFA) was initially conducted on the 25 items of IPI(M) scale to access the quality of the factor structure by statistically testing the significance of the overall model of to access the goodness-of-fit of the new measure construct. The CFA results confirmed that the measurement scale used in this study satisfactorily met the standards of validity and reliability analysis and showed acceptable internal consistency reliability for the overall and the five specific subscales of power factor. The IPI(M) construct provides a multi-dimensional assessment tool to diagnose and guide leader social power in the Malaysian organizational context.
\end{abstract}

Index Terms-Coercive power, expert power, interpersonal power inventory, leader power, legitimate power, referent power, reward power.

\section{INTRODUCTION}

Social Power (SP) has a significant impact on the implementation of the strategies, policies, and decision making in organization and it can be an extreme tool in the success or failure of an organization. While its phenomenon has been well documented across the social science researchers to understand human behavior, its definition has been described in myriad of ways in the social sciences literature. As SP has been studied from various perspectives and described by many different sociological and psychological theories, its intricacy and understandable provide a wide variety of definitions and operationalizations [1]. A commonly cited definition is that of [2]-[4] who define social power as the ability on one person to change or control

Manuscript received January 10, 2014; revised March 11, 2014.

The authors are with the Faculty of Business Management, Universiti Teknologi MARA, Bandar Puncak Alam, Selangor, Malaysia (e-mail: rozilah@puncakalam.uitm.edu.my, shereen@puncakalam.uitm.edu.my, sharrifah@puncakalam.uitm.edu.my). behavior, attitudes, opinions, objectives, needs, and values of other person. This definition gives the implication that research on power is limited to the influence of one individual (leader) or supervisory power over another individual (follower) (rahim). Evidence shows that the term "influence," "power," "decision-making," "authority' and other terms have often been used interchangeably [5].

Considering the importance of the IPI (M) construct, and the development of an interest in social power, it warrants an intensive research on the SP construct that is suitable and applicable to the Malaysian organizational climate. Furthermore, very few attempted to review and assess the IPI conceptualization of social power bases in Malaysia.

\section{LITERATURE REVIEW}

Over the years, the study of power sources has become a central concept in organizational psychology, as well as in other analyses of social interaction. Evidences showed numbers of instruments developed by other investigators were derived from a priori proposition made by [6] typology who suggested 5 bases of power taxanomy: (a) reward power - promise of monetary or nonmonetary compensation; (b) coercive power - threat of punishment; (c) legitimate power drawing on one's right to influence; (d) expert power relying on one's superior knowledge; and (e) referent power - based on target's identification with influencing agent [7]. These conceptualizations derived from the early work of [8], who posited a model of human behavior based upon forces within one's life space.

In a later elaboration, based on presentation of persuasive material or logic, informational power was also considered as a basis of power as it conceived as distinct from expert power. However, despite the broad acceptance of this typology of power in survey texts of social and organizational psychology, [7] identified some serious methodological and substantive concerns. Concerns have been raised in regard to conceptual overlaps between categories, inconsistent operational definitions, and, at times, low agreement between observation and prediction [3]. For example, allusions to expertise may involve many elements of referent and informational power. This problem was heightened by the fact that differing power bases are often used in combination (e.g expert and informational power), that influencing supervisors tend to reveal profiles of powers using unique constellations of bases rather than simple clear preferences for individual bases [9]-[11].

Finally, several other investigators using different methodological approaches argued that the number of power sources may be greater than the five or six in the original formulation [12], [13] identified another two power sources; 
persuasiveness and charisma, which did not appear in the original French and Raven Taxanomy. However, their definition of persuasiveness overlaps with Raven's [14] definition of information, and charisma was seen as a projected character trait which was closely related to referent power. [15] reported a nine-factor taxanomy (rational persuasion, inspirational appeal, consultation, negotiation, exchange, personal appeal, collision, legitimating, and pressure). [16], [17] presented Interpersonal power/interaction model. In this model, while maintaining the basic conception of six bases of power, evidence was cited from theory and research affirmed the need to make differentiations among some of the bases of power [3]. Coercion and reward power which were conceptualized in terms of "impersonal" threats or promises of reward are now distinguished from personal coercion and personal reward [3] Raven's new approach further differentiated coercion, reward and legitimate power (coercion power, personal coercion power, reward power, personal reward power and added (a) legitimate position power - supervisor's right to prescribe behavior for the subordinates; (b) legitimate reciprocity - stems from the target's obligation to comply with supervisor's request after the supervisor has done something positive for the subordinate; (c) legitimate equity - draws on the equity norm where supervisor demands compliance to compensate; and (d) legitimate - dependencebased on a social responsibility norm which obliges one person to assist another who is in need of assistance ).

IPI presented a situation where a subordinate, though initially reluctant, eventually complies with the supervisor's request [3]. As a result, IPI is developed with 11 bases of power: the original 6 French and Raven [6] bases of power, with 3 of these further differentiated; reward (personal, impersonal), coercion (personal, impersonal), legitimate (position, reciprocity, equity, dependence), expert, referent, and information. In this study, it was reported that each of these power bases contributed to a supervisor successfully influencing a subordinate in a series of hypothetical situations. The internal consistency of the items which made up the 11 power bases proved adequate.

In most study, social power is mainly measured by French and Raven Power Taxonomy because there is extensive evidence of psychometric properties of the instruments in various different samples. Nevertheless, [3] argued that a number of scales developed by others to measure the original 5 or 6 bases of power often failed to fully satisfy the conceptual definitions of the bases of power as originally presented. For that reason (Rozilah, 2013) developed a new instrument of social power called IPI (M) with 5 bases of power taxanomy. Considering the importance of the social power construct, the intricacy and understandable in its definition and quantification, it warrants an intensive research on the IPI(M) construct that is suitable and applicable to the Malaysian organizational context. In most instances, psychometric analyses of IPI were limited to exploratory factor analyses as well as the predictive validity of the construct. Hence, the focus of this study was to observe the gap by examining the construct validity and empirical dimensionality social power construct by employing IPI(M) as an instrument to evaluate the aforesaid construct through convergent validity and discriminant validity. The items and dimension of IPI(M) were developed and adapted based on [3] that assessed 11 dimensions of LSP: the original 6 French and Raven bases of power, with 3 of these further differentiated; reward (personal, impersonal), coercion (personal, impersonal), legitimate (position, reciprocity, equity, dependence), expert, referent, and informational power.

Therefore, in accessing the construct validity of IPI(M) an exploratory factor analyses (EFA) and a confirmatory factor analyses (CFA) were utilized. An EFA was conducted to test the validity and reliability of IPI as well as identifying obvious poor loadings of items under each dimension. [18]. CFA was conducted to assess the quality of the factor structure by statistically testing the significance of the overall model and of item loadings on factors. The purpose of the analysis is to assess the goodness-of-fit of the new measure constructs and allows more precision in evaluating the measurement model [19]. The construct validity of the factor was assessed in terms of Variance Extracted (VE), Construct or Composite Reliability (CR) as well as standardized factor loadings in the measurement model for evidence of convergent validity and Average Variance Extracted (AVE) for discriminant validity [19]. Overall, the EFA and CFA purposes of this study were conducted to examine the stability of the factor structure and provide information that would facilitate the refinement of a new IPI measure. Subsequently, a scale development which includes an assessment of the psychometric properties of the scale was constructed. It is necessary to administer the potential items to a representative sample in order to examine how well the items confirm expectations related to the structure of the measure in question [18]. The scale has been consistently administered and the psychometric properties of this scale have been highly reliable.

\section{MATERIALS AND METHOD}

\section{A. Procedures}

A sample size of 101 employees working directly under HR Managers was used as a pilot study to analyze the data. Earlier, an exploratory factor analysis (EFA) was conducted to test the validity and relibility of IPI raven [3]. The EFA analysis has confirmed 5 dimensions of IPI namely Reward, Coercive, Legitimate, Expert and Referent powers respectively. The name of the IPI was then, changed to IPI(M) for the purpose of further research in Malaysian organizational context. In this study, the IPI(M) items were rated on a 6-point likert scale: 1) strongly disagree, 2) moderately disagree, 3) disagree, 4) moderately agree, 5) agree, 6) strongly agree.

\section{B. Analytical Procedure}

Data were analyzed using Statistical package for Social Science (SPSS) version 18 and Analysis of Moments Structure (AMOS) version 19. The reliability and initial evidence of validity were reported based on results from Cronbach's alpha reliability and EFA. The EFA on the latent construct was carried out to determine if the responses gathered can be grouped according to items in each of the hypothesized dimensions. Following [18]-[21], EFA using principal axis factoring varimax rotation and a priori data of 5 factors was conducted to analyze factor structure of the 
construct. The cutoff point of 0.5 was used as the threshold to ensure practical significance for further analysis [19]. Then, measurement model or CFA for each latent factor was examined by observing the model fit level. Based on [19], [18], convergent validity in this study was assessed by calculating the VE and CR of each latent construct.

To analyze and generate sufficient variance among respondents for subsequent statistical analysis as well as identifying and confirming the underlying structure of the 44 items of IPI, a sample size of 101 executives working directly under Human Resource Managers (HR Managers) was used as a pilot study. Then, the new set of survey questionnaire generated from EFA results were distributed to new respondents. A sample size of 388 of executives working directly under HR Managers was used to conduct the statistical significance test as well as to evaluate the measurement model more precisely. CFA was conducted to assess the quality of the factor structure by statistically testing the significance of the overall model and of item loadings on factors. The purpose of the analysis is to assess the goodness-of-fit of the new measure constructs and allows more precision in evaluating the measurement model [19].

\section{RESUlTS AND DISCUSSIONS}

\section{A. Reliabilit and Construct Validity (EFA)}

Construct validity refers to whether a scale measures or correlates with a theorized psychological construct [18]. To examine IPI competencies scale the EFA with varimax rotation was performed to identify and confirm the underlying structure of the items. Initially, the suitability of the data for factor analysis was explored. A second round of EFA analysis was conducted to confirm the underlying structure of the new 25 items IPI scale. Table I illustrates the final round of EFA analysis which confirmed 5 dimensions of IPI(M) namely Reward, Coercive, Legitimate, Expert, and Referent Power. The new IPI(M) scale that consist of 25 items shows that the KMO measure of sampling adequacy has increased to 0.899 , exceeding the recommended value of 0.6 [22], indicating that the sample size was adequate to factor analyze the 25 items. The Chi-Square value of Bartlett's Test of Sphericity, for the 25 items correlations matrix was highly significant $(p<0.000)$, reached statistical significance, supporting the factorability of the correlation matrix [23]. An eigenvalue of 1.0 was set as the minimum criterion for identifying a factor and used as a cutoff value for extraction. The factor analysis extracted five factors which the total variance explained for this construct was $72.22 \%$ with factor loadings exceeding 0.5 . The percentages of variance explained for each factor were $36.24 \%, 18.53 \%$, $8.02 \%, 5.15 \%$, and $4.28 \%$ respectively. The eigenvalues of of the five factors were $20.47,18.6,7.7,2.14$, and 1.36 . The factor loadings for all the remaining items range from 0.617 to 0.812 . All of the items in IPI variables have exhibit value ranging from 0.82 to 0.90 cronbach's alpha. The scree plot confirmed that five factors should be retained. Therefore, five factors or domains were retained.

In the light of the rotated component matrix, the model confirmed the presence of five IPI having 5 items were allocated to the first factor named referent power, and the second factor consists of 5 items named coercive power. The third factor with 5 items, named legitimate power, fourth factor consists of 5 items named expert power, and 5 items were also allocated to the fifth or last factor named referent power. It was proved in this study that the IPI(M) Scale is valid (in terms of construct validity), acceptable and suitable tool to be used in social power of a leader in Malaysia.

\section{B. Convergent Validity (CFA)}

Further to the construct validity test using the factor analysis (between scales) another factor analysis but this time using the within scale was utilized to the tconvergent validity. A sample of 338 executives working directly under HR Managers was used for data analysis. Further to the construct validity test using the factor analysis (between scales) another factor analysis using the within scale was conducted to test the convergent validity. Convergent validity was carried out through a within factor in order to obtain a more in-depth judgment of the dimensionality of the construct under study [20]. Specifically, convergent validity identifies the proportion of variance for each factor. Convergent validity was assessed based on the factor loading, composite reliability (CR), and average variance extracted (AVE) [19]. Table II summarizes the results of internal reliability and convergent validity for the five constructs of IPI. The factor loading for all items in this study exceeded the recommended level of 0.60 . CR which depicts the degree to which the construct indicators indicate the latent construct, ranged from 0.870 to 0.952 exceeding the recommended level of 0.7 which was suggested by [24]. The AVE which reflects the overall amount of variance in the indicators accounted for by the latent construct, were in the range between 0.574 and 0.798 , exceeding the recommended level of 0.5 as suggested by [20]. Hence, the analysis provides support for convergent validity.

TABLE I: THE PSYCHOMETRIC PROPERTIES OF THE FIVE DIMENSIONS OF THE IPI(M), 2013

\begin{tabular}{|c|c|c|c|c|c|}
\hline Factor & Item & Loadings & Comonalities & MSA & $\alpha$ \\
\hline Reward & RP1 & 0.638 & 0.630 & 0.899 & 0.901 \\
\hline \multirow[t]{4}{*}{ Power } & RP2 & 0.705 & 0.712 & & \\
\hline & RP3 & 0.742 & 0.771 & & \\
\hline & RP4 & 0.809 & 0.720 & & \\
\hline & RP5 & 0.750 & 0.767 & & \\
\hline Coercive & CP6 & 0.733 & 0.636 & 0.769 & 0.827 \\
\hline \multirow[t]{4}{*}{ Power } & $\mathrm{CP} 7$ & 0.854 & 0.808 & & \\
\hline & CP8 & 0.812 & 0.810 & & \\
\hline & CP9 & 0.705 & 0.868 & & \\
\hline & CP10 & 0.637 & 0.785 & & \\
\hline Legitimate & LP11 & 0.654 & 0.686 & 0.719 & 0.844 \\
\hline \multirow[t]{4}{*}{ Power } & LP12 & 0.617 & 0.621 & & \\
\hline & LP13 & 0.667 & 0.751 & & \\
\hline & LP14 & 0.668 & 0.679 & & \\
\hline & LP15 & 0.731 & 0.773 & & \\
\hline \multirow[t]{5}{*}{ Expert Power } & EP16 & 0.829 & 0.740 & 0.870 & 0.815 \\
\hline & EP17 & 0.755 & 0/792 & & \\
\hline & EP18 & 0.729 & 0.720 & & \\
\hline & EP19 & 0.802 & 0.718 & & \\
\hline & EP20 & 0.764 & 0.679 & & \\
\hline Referent & RfP21 & 0.666 & 0.685 & 0.892 & 0.834 \\
\hline \multirow[t]{4}{*}{ Power } & RfP22 & 0.820 & 0.734 & & \\
\hline & RfP23 & 0.886 & 0.793 & & \\
\hline & RfP24 & 0.727 & 0.751 & & \\
\hline & RfP25 & 0.787 & 0.733 & & \\
\hline
\end{tabular}




\section{Discriminant Validity}

Next, discriminant validity which measures the degree to which the measures of different concepts are distinct was examined. Discriminant validity examines the extent to which an independent variable is truly distinct from other independent variables in predicting the dependent variable [19]. Discriminant validity can be examined by comparing the correlations between constructs and the square root of the variance extracted for a construct [24]. Table III illustrated that the correlations for each construct was less than the square root of the AVE by the indicators measuring that construct indicating that the measure had adequate discriminant validity. In summary the measurement model demonstrated adequate reliability, convergent validity, and discriminant validity.

TABLE II: CONVERGENT VALIDITY

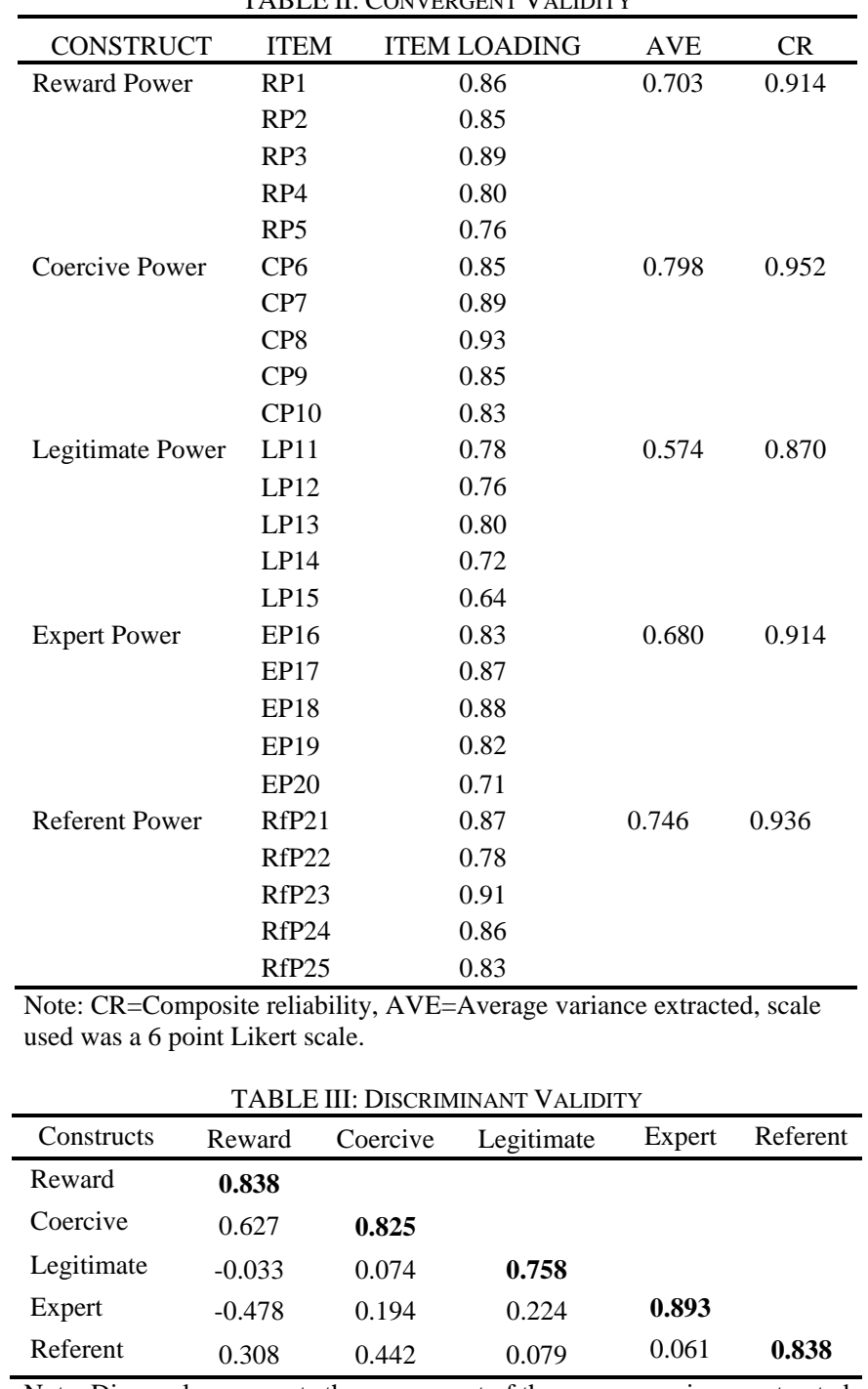

Note: Diagonals represents the square root of the average variance extracted while the other entries represent the correlations.

\section{First Order and Second Order IPI Measurement Model}

The measurement model was observed for overall fitness by referring to other fit indices as suggested by [18] and [21]. The fit indices reported in this study were the root mean square error of approximation (RMSEA $\leq 0.80)$, the comparative fit indices $(\mathrm{CFI} \geq 0.90)$, the goodness-of-fit indices $(\mathrm{GFI} \geq 0.90)$ and the acceptable range for Normed Chi-square $\leq 3$ for model parsimony [18], [19], and [25]. IPI scale were originally measured by 44 items. However, based on the EFA results, 19 items were deleted due to low factor loading, i.e., <0.05. Hence, only 25 items were subjected to CFA. Fig. 1 shows the first order measurement model with good fit of CFI $=0.981, \mathrm{GFI}=0.920, \mathrm{RMSEA}=0.038$, and the normed Chi-square $=1.546$. Likewise, the second order measurement model also demonstrated good fit with CFI = 0.971 , GFI $=0.906$, RMSEA $=0.046$, and the Normed Chi-square $=1.812$. This results shows support for the convergent validity of the model. Model fit statistics comparing both factor models are shown in Fig. 1 and Fig. 2. The results indicated that the 2 measurements models for IPI construct met the criteria for good fitting models. The second order reproduced similar results to the earlier first order factor. This finding suggests for validity and utility for the first order and second order measurement model of IPI(M) in evaluating leader social power in the Malasian organizational context.

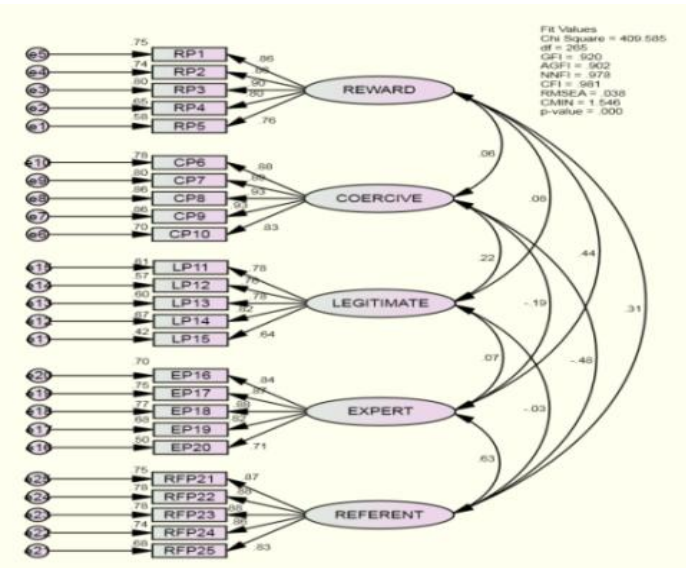

Fig. 1. First order full measurement model for IPI

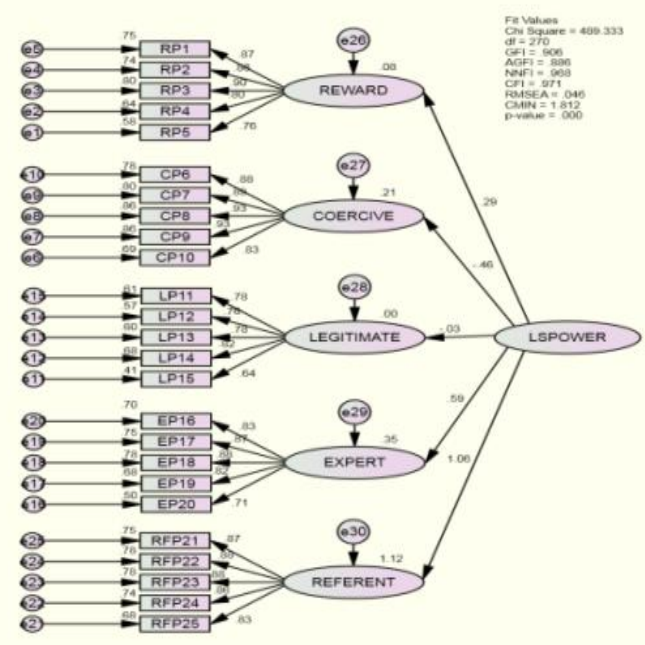

Fig. 2. Second order full measurement model for IPI

\section{CONCLUSION}

The current study provides evidence of robustness of IPI in terms of construct validity. This is based on the fact that EFA and CFA results yielded 5 dimensionality of social power measured by IPI (M). Additionally, CR for each dimension were all above 0.60 , variance extracted were all exceeded 0.50 and standardized factor loading all $>0.5$. In terms of 
discriminant validity, the results show evidence that all dimensions in IPI (M) were distinct of one another. This study also reported coefficient alphas were $>0.60$ for all dimensions in social power, indicating evidence of internal consistency reliability of all items in IPI (M). Based on the results, IPI (M) can be usable in the Asian context, particularly the Malaysian organization setting because of the evidence of construct validity of items in IPI (M). Most importantly, to the best of the researcher's knowledge, only a few studies had been conducted to attest the construct validity of IPI (M). This is because most of the results that reported psychometric properties of IPI (M) were strictly based on the results of EFA and internal consistency reliability. This study has moved one step ahead in evaluating the robustness of the Malay-translated version of IPI in terms of construct validity to establish usability of the instrument in the Malaysian organization setting, particularly in the GLCs. As a conclusion, the results of this study suggest good reliability and validity of the instrument. Most importantly, CFA provided the empirical evidence of construct validity based on assessment of the psychometric properties and measurement model fit for IPI (M). As a whole, the Malay translated version of IPI(M) measuring 5 subscales of IPI can be useful instrument in assessing social power construct in Malaysia, particularly in GLCs setting due to the of construct validity of the instrument. The significance of this measurement lies in the fact that departing from the majority of the existing research that focuses on the social power on job commitment, job satisfaction and other variables, this research is about the instrument used to measure the above-mentioned social power.

\section{ACKNOWLEDGMENT}

Authors would like to express our appreciation to Prof. Dr. Schwarzwald for his kindness in giving the permission to use the IPI instrument to be re-evaluated and used in the Malaysian organizational settings. Table I: The Psychometric properties of the five dimenstions of the IPI(M) [26].

\section{REFERENCES}

[1] V. P. Richmond and J. C. McCroskey, Organizational Communication for Survival: Making Work, Work, 10th ed., 2009.

[2] J. R. P. French and B. Raven, "The bases of social power," The Negotiation Sourcebook, pp. 61-74, 2001

[3] B. H. Raven, J. Schwarzwald, and M. Koslowsky, "Conceptualizing and measuring a power/interaction model of interpersonal influence," Journal of Applied Social Psychology, vol. 28, pp. 307-332, 1998.

[4] D. Cartwright and A. Zander, "Power and influence in groups: Introduction," Group dynamics: Research and Theory, pp. 580, 1968.

[5] M. Koslowsky, H. Baharav, and J. Schwarzwald, "Management style as a mediator of the power distance-influence tactics relationship," International Journal of Conflict Management, vol. 22, pp. 264-277, 2011.

[6] B. H. Raven and J. R. P. French, "Legitimate power, coercive power, and observability in social influence," Sociometry, pp. 83-97, 1958.

[7] P. M. Podsakoff and C. Schriesheim, "Leader reward and punishment behavior: A methodological and substantive review," B. Staw and $L L$ Cummings, pp. 38-52, 1985.

[8] K. Lewin, "Field theory in social science: selected theoretical papers (Edited by Dorwin Cartwright)," 1951.

[9] D. Kipnis, Technology and Power, Springer-Verlag Publishing, 1990.

[10] C. A. Schriesheim and T. R. Hinkin, "Influence tactics used by subordinates: A theoretical and empirical analysis and refinement of the Kipnis, Schmidt, and Wilkinson subscales," Journal of Applied Psychology, vol. 75, p. 246, 1990.
[11] M. A. Rahim, "Toward a theory of managing organizational conflict," International Journal of Conflict Management, vol. 13, pp. 206-235, 2002.

[12] D. Kipnis and S. M. Schmidt, "An influence perspective on bargaining within organizations," Negotiating in Organizations, pp. 303-319, 1983.

[13] G. Yukl and C. M. Falbe, "Importance of different power sources in downward and lateral relations," Journal of Applied Psychology, vol 76, p. 416, 1991

[14] B. H. Raven, "The bases of power and the power/interaction model of interpersonal influence," Analyses of Social Issues and Public Policy, vol. 8, pp. 1-22, 2008

[15] G. Yukl and J. B. Tracey, "Consequences of influence tactics used with subordinates, peers, and the boss," Journal of Applied Psychology, vol. 77, p. 525, 1992.

[16] B. H. Raven, "A power/interaction model of interpersonal influence: French and Raven thirty years later," Journal of Social Behavior and Personality, 1992.

[17] B. H. Raven, "The bases of power: origins and recent developments," Journal of Social issues, vol. 49, pp. 227-251, 1993.

[18] B. Byrne, "Structural equation modelling using AMOS," Basic Concepts, Applications, and Programming, 2010.

[19] J. Hair, W. Black, B. Y. A. Babin, R. Anderson, and R. Tatham, RE [2010]: Multivariate Data Analysis a global Perspective, Pearson Prentice Hall.

[20] J. Pallant, SPSS Survival Manual: A Step by Step Guide to Data Analysis Using SPSS, Open University Press, 2010.

[21] B. G. Tabachnick and L. S. Fidell, Experimental Designs Using ANOVA, Thomson/Brooks/Cole, 2007.

[22] H. F. Kaiser, "An index of factorial simplicity," Psychometrika, vol. 39, pp. 31-36, 1974.

[23] M. S. Bartlett, "A note on the multiplying factors for various $\chi 2$ approximations," Journal of the Royal Statistical Society Series B (Methodological), pp. 296-298, 1954

[24] D. Gefen, D. W. Straub, and M.-C. Boudreau, "Structural equation modeling and regression: Guidelines for research practice," 2000.

[25] R. Schumaker, "Lomax," A Beginner'S Guide to Structural Equation Modeling, 2004.

[26] A. A. Rozilah, H. Narehan, M. S. Rohana, N. Shereen, and A. Sharrifah, "Exploratory factor analysis: conceptualization, reliability and validity of interpersonal power inventory," 2013.

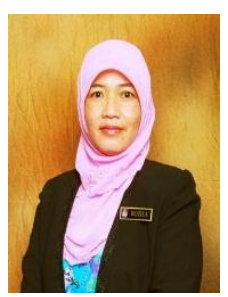

Rozilah Abdul Aziz was born in, Kuala Lumpur, Malaysia. She is a postgraduate student at Universit Teknologi Mara, Shah Alam and currently conducting a doctoral research in the field of Organizationa Communication. Rozilah has obtained her MSc. in corporate communication, Universiti Putra Malaysia (UPM) and BBA in business administration, Western Michigan University, USA. She is currently a senior lecturer at the Faculty of Business Management in Universiti Teknologi MARA, Shah Alam. Her areas of interest include organizational communication, human communication, organizational behavior and human resource management.

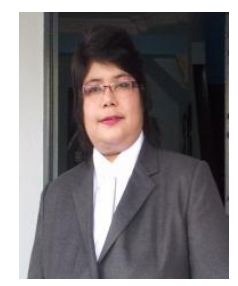

Narehan Hassan was born in Klang, Malaysia. She holds a Ph.D. in Education (Student Development) from Southern Illinois University, United States. She held many positions including confidential secretary, tutor, and training manager in Malaysia before embarking on academic discipline and obtained all of her tertiary degrees from American universities. She was also a teaching assistant while studying at the post graduate level in the USA. She has more than 25 years of teaching experience in adult education. Right now, she is an associate professor at the Center for Applied Management, Faculty of Business Management, University Teknologi MARA, Malaysia.

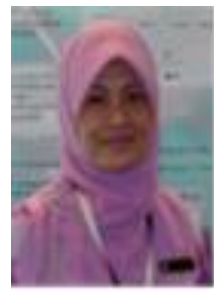

Shereen Noranee is a senior lecturer/Ph.D candidate, of Universiti Teknologi Mara Malaysia, Puncak Alam, Selangor, Malaysia. She holds a MSc. in human resource development from the Universiti Putra Malaysia, Malaysia and BSc. in business education from University of Nebraska-Lincoln, USA. Her research interest includes human resource management, organizational, organizational psychology and organizational behavior. 